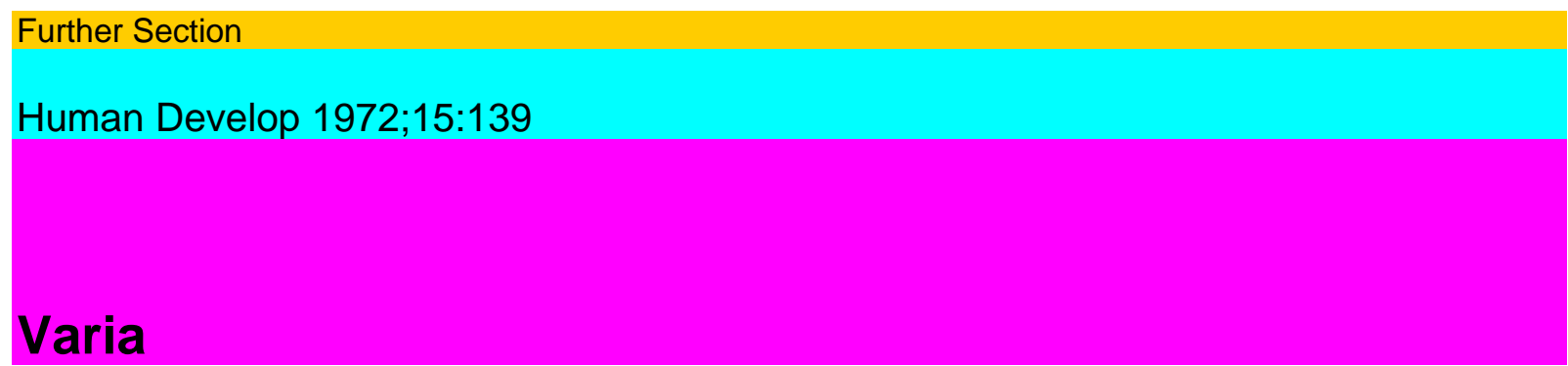

Genetic and Social Influences on Psychological Development

Methodological Approaches and Research Results

A report on the first symposium of the International Society for the Study of Behavioral

Development, held at the University of Nijmegen, Department of Developmental Psychology, July 4-8, 1971, organized by F. Monks, University of Nijmegen, N.W. Hartup, University of Minnesota, H. Thomae, University of Bonn, J. de Wit, Free University

\title{
of Amsterdam
}

The international character of the society was evidenced by the participation of 269 persons from the following 19 countries: Austria (3), Belgium (15), Canada (3), Czechoslovakia (3), Denmark (5), Finland (2), France (3), Germany (22), Indonesia (2), Israel (6), Italy (11), Japan (2), The Netherlands (84), Norway (3), Poland (1), Sweden (15), Switzerland (3), United Kingdom (25), USA (63).

To realize as much as possible the scientific integration which the society aims to achieve, full sessions were scheduled besides small-group meetings. The Society's aim to deal with the entire domain of behavioral development was reflected by the variety of topics presented. Since the proceedings will be published in book form only listing of the major themes is included here. Each of the 18 invited speakers addressed the convention on one of the following topics: Genetic influences on behavioral development; Social class and development; Cultural and social factors in development; General methodological problems in the study of genetic and social influences; Problems of research strategy; Longitudinal studies; Cross-cultural research.

A colloquim, 'Enrichment and Deprivation', was presented by L. Yarrow, J. Lang-meier, J. Gewirtz, L. Kohlberg and J. de Wit, and concluded with a discussion led by W. W. Hartup. In addition to the major addresses, the program included 9 small-group sessions with 43 speakers. The lectures and discussions during the symposium suggested that the large amount of existing research material enhances the need for: (1) the development of new theoretical models, as well as the extension of existing models (Riegel: 'The changing individual in the changing society'); (2) greater emphasis on research methodology and theoretical generability (Stevenson: 'The taxonomy of tasks'); and (3) an increased emphasis on the biological and genetic aspects of human behavior (Freedman: 'Genetic variations on the hominid theme: Individual, sex and ethnic differences').

The international emphasis of the society will be continued with the second symposium scheduled for Kyoto, Japan in the Fall of 1972.

J. Lempers, J. Verhoeven and J. Verlinden 